\title{
Probabilistic climate change scenarios for viticultural potential in Québec
}

\author{
Philippe Roy ${ }^{1}$ (D) . Patrick Grenier ${ }^{1}$. \\ Evelyne Barriault ${ }^{2}$ • Travis Logan ${ }^{1}$ • Anne Blondlot ${ }^{1}$. \\ Gaétan Bourgeois $^{3}$ - Diane Chaumont ${ }^{1}$
}

Received: 13 May 2016 / Accepted: 21 March 2017 / Published online: 8 May 2017

(C) The Author(s) 2017. This article is an open access publication

\begin{abstract}
Climate conditions for Québec's viticultural potential (VP) during upcoming decades are estimated through high-resolution probabilistic climate scenarios (PCS) based on a large ensemble of simulations from the Coupled Model Intercomparison Project Phase 5 (CMIP5). VP is investigated through four temperature-related indices identified as current limiting factors for cold, northern latitudes: length of frost-free season (CNFD), growing degree-days (DDB10), annual winter minimum temperature (AWMT), and annual number of very cold days (ANVCD). Results show that by 2040-2050, most of southern Québec can reasonably expect favorable climatic conditions, with enough consecutive frost-free days and growing degree-days for growing current hybrid-grape varieties, as well as some Vitis vinifera grape varieties. Regions with new VP are identified, for example southern Outaouais and along the St-Lawrence River. Cold winter temperatures remain problematic, but technical solutions to this limiting factor exist.
\end{abstract}

\section{Introduction}

Viticultural viability and quality of a given region depends strongly on climate, with interannual climate variability playing an important role in wine quality (Jones et al. 2005; Jones

Electronic supplementary material The online version of this article

(doi:10.1007/s10584-017-1960-x) contains supplementary material, which is available to authorized users.

Philippe Roy

roy.philippe@ouranos.ca

1 Ouranos, 550, rue Sherbrooke Ouest, Montréal, Québec, Canada

2 Ministère de l'Agriculture, des Pêcheries et de l'Alimentation du Québec (MAPAQ), 109, rue Saint-Charles, bureau 1.01B, Saint-Jean-sur-Richelieu, Québec, J3B 2C2, Canada

3 Agriculture and Agri-Food Canada, 430 Gouin Boulevard, Saint-Jean-sur-Richelieu, Québec, J3B 3E6, Canada 
and Webb 2010) while extreme temperatures (hot and cold) act as important limiting factors for viability (White et al. 2006). Furthermore, climate change has already had measurable impacts on the wine industry worldwide (Battaglini et al. 2009; Jones 2012). During the next decades, evolving climatic conditions could result in the collapse of currently vulnerable wineproducing regions, as well as the rise of new ones (White et al. 2006; Hannah et al. 2013).

Factors influencing viticultural potential (VP) are not only climatic. Non-climatic factors include soil type and quality (drainage, depth, texture, and acidity), slope magnitude and direction as well as altitude, to name a few. However, the main challenge for winemakers in high-latitude regions remains climate constraints (Jones 2012). More specifically: length of the frost-free season (and the implicit risk of freezing around the bud-break period), the accumulation of heat during the ripening period and finally harsh winter minimum temperatures (Shaw 1999). As such, this study examines only climatic factors for agricultural regions in the province of Québec, situated in northeastern North America (Fig. 1).

Southern Québec is located at latitudes comparable to southern France, but cannot presently exploit vine varieties such as those grown in Bordeaux for example, partly due to climatic differences, with harsh winters being a major difference. Measured bright-sunshine hours are higher in southern Québec than Bordeaux, Languedoc and New Zealand (Jones 2012). A wine industry developed about four decades ago in Québec, with the first commercial winery (La Vitacée) established in 1977 in Sainte-Barbe (Dubois 2001) and an estimated increase in total stock from 82,925 vine stocks in 1985 to 512,000 in 2000 (Dubois 2001),

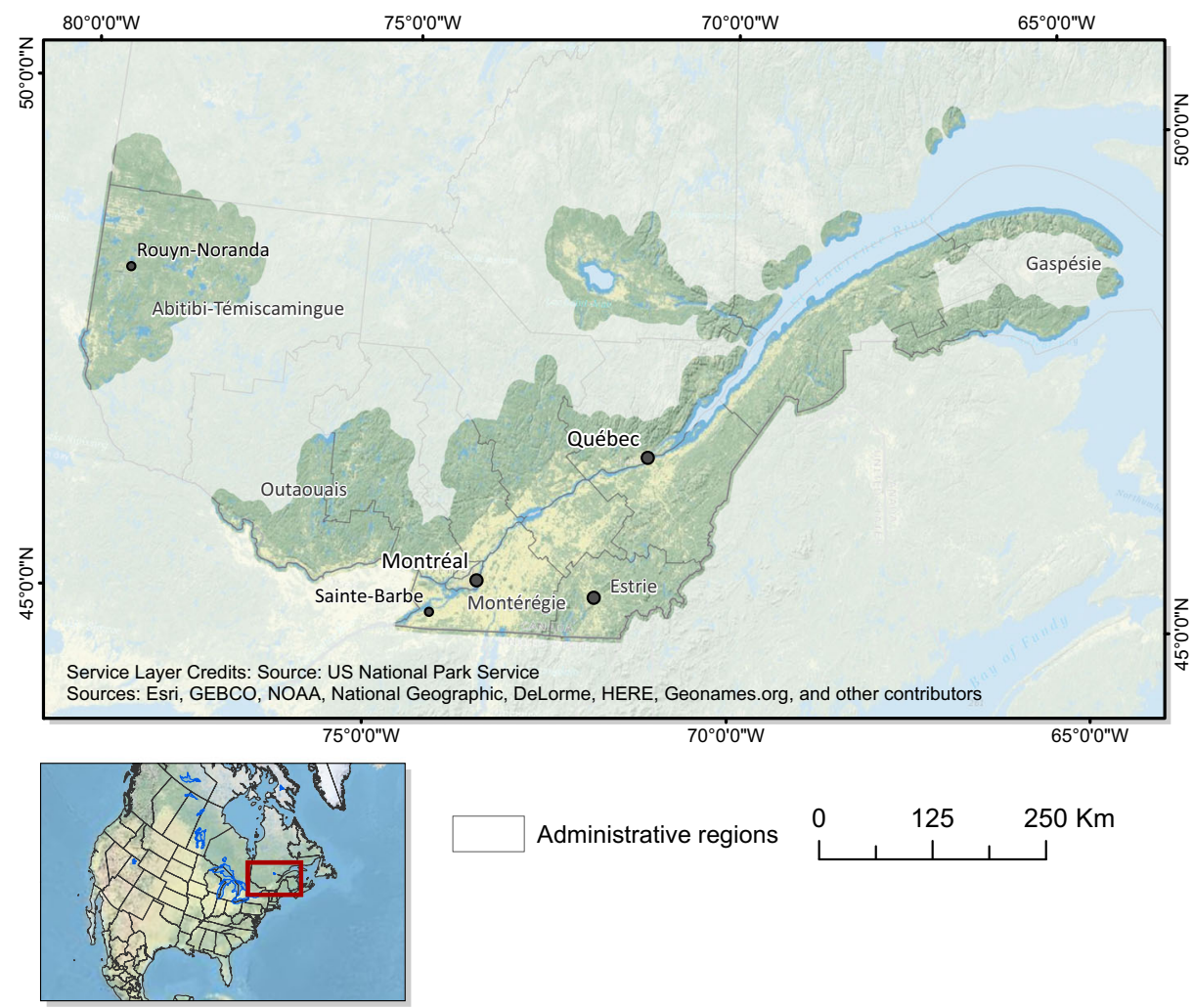

Fig. 1 Agricultural region in the state of Québec. This region is located in northeastern North America 
representing a fivefold growth in only 15 years. Since 2000, the sector has continued to grow rapidly, and in early 2017 , there were 142 wine-category permits issued by the Régie des alcools des courses et de jeux du Québec (personal communication).

Due to climatic constraints, most winegrowers select grapes varieties that are suitable for a cold climate. Moreover, since southern Québec is not a traditional viticultural region, the recognition and marketing of the cold-hardy hybrid grapes varieties remains challenging. Observed climatic change over recent decades has prompted some winegrowers to grow Vitis viniferas (e.g., Pinot Noir, Cabernet Franc, Chardonnay), which typically attract higher prices, as they are well recognized around the world for their organoleptic qualities (Wolf 2008).

Here, we show the evolution of Québec's VP over 1961-2070 (Fig. 1), using probabilistic climate scenarios (PCS) (e.g., Palmer and Räisänen, 2002; Tebaldi and Knutti 2007). PCS is an approach used to assign a probability-density function to a climate variable or a probability for a given event to occur, based on an ensemble of climate scenarios. While such an approach cannot avoid subjective assumptions (Parker 2010), it has legitimacy based on the fact that in the absence of pragmatic information, decision-makers will implicitly build their own probabilities, which may depart substantially from experts' best guess (Hall et al. 2005).

Also shown is the degree to which future climate conditions indicate potential for growing $V$. vinifera, derived from climate-indicator thresholds associated with early ripening $V$. vinifera grape varieties such as Pinot Noir, Gamay, and Chardonnay. Under climate change, limiting conditions are expected to approach or exceed suitability thresholds for $V$. vinifera, increasing the potential to grow this variety.

\section{Methods}

\subsection{Data}

This study is based on a large ensemble of climate scenarios from the Coupled Model Intercomparison Project Phase 5 (CMIP5) simulations (Taylor et al. 2011). A climate scenario is defined as a plausible future climate trajectory and is generally obtained by a post-processing method, which roughly consists of merging the observed historical climate information with the future trends simulated by a numerical climate model (Themeßl et al. 2012; Gennaretti et al. 2015). Uncertainty regarding the future climate trajectory is traditionally split into three sources: future anthropogenic emissions, variety in model formulation and natural climate variability (Hawkins and Sutton 2011).

Representative Concentration Pathways (RCP) 4.5 and 8.5 have been adopted as lower and higher boundaries for uncertainty of the "emissions" type. Simulations forced by these two RCPs form two distributions in terms of warming that start diverging around 2040 and still overlap in 2100. RCP2.6 has been judged too unrealistic during the second half of the 21st century to be used, and RCP6.0 already lies within the RCP4.5-RCP8.5 interval. The "model" and "natural variability" types of uncertainty are covered by the consideration of 26 models and 94 simulations.

\subsection{Climate indices}

VP was assessed through four annual climate indices (Table 1) describing the main factors contributing to vine growing. The definitions of indices have been developed by grape and wine advisors (Barriault et al. 2013) to ensure that their definitions and thresholds represent 
Table 1 Climate indices used for the assessment of viticultural potential

\begin{tabular}{|c|c|c|}
\hline Name (units) & Definition & Thresholds (suitability) \\
\hline CNFD (days) & $\begin{array}{l}\text { Maximum number of consecutive } \\
\text { days without frost }\left(\operatorname{Tmin}>=-2{ }^{\circ} \mathrm{C}\right)\end{array}$ & $\begin{array}{l}<150 \text { (unsuitable) } \\
>150 \text { (low) } \\
>156 \text { (moderate) } \\
>166 \text { (good) } \\
>180(\text { very good })\end{array}$ \\
\hline $\operatorname{DDB} 10\left({ }^{\circ} \mathrm{C}\right)$ & $\begin{array}{l}\text { Growing degree days with base } 10 \\
\text { between April 1st and October } 31 \text { st }\end{array}$ & $\begin{array}{l}<900 \text { (unsuitable) } \\
>900(\text { low }) \\
>1000(\text { moderate }) \\
>1100(\text { good }) \\
>1250(\text { very good })\end{array}$ \\
\hline AWMT $\left({ }^{\circ} \mathrm{C}\right)$ & Annual winter minimum temperature & $\begin{array}{l}<-34 \text { (unsuitable) } \\
>-34 \text { (low) } \\
>-30 \text { (moderate) } \\
>-27 \text { (good) } \\
>-22(\text { very good })\end{array}$ \\
\hline ANVCD (days) & $\begin{array}{l}\text { Annual number of very cold days } \\
\left(<-22^{\circ} \mathrm{C}\right)\end{array}$ & $\begin{array}{l}>30 \text { (unsuitable) } \\
<30 \text { (low) } \\
<20 \text { (moderate) } \\
<10 \text { (good) } \\
<5 \text { (very good) }\end{array}$ \\
\hline
\end{tabular}

real potential from climatic factors in the province of Québec. The first index (CNFD) is the length of the frost-free season and is defined as the maximum number of consecutive days without frost condition ( $\operatorname{Tmin} \geq-2{ }^{\circ} \mathrm{C}$ ). The second index (DDB10) is the daily heat accumulation over $10{ }^{\circ} \mathrm{C}$ between April first and October 31st. It is defined as the summation of daily mean values minus $10{ }^{\circ} \mathrm{C}$ (if the daily mean value is over $10{ }^{\circ} \mathrm{C}$ ). The third index (AWMT) is the annual winter minimum temperature. The fourth index (ANVCD) is the annual frequency of minimum temperatures below $-22{ }^{\circ} \mathrm{C}$.

These thresholds can be linked to some grape varieties. As stated earlier, hybrid grape varieties need less heat accumulation than $V$. vinifera. For example, Frontenac (1150 GDD), Marechal-Foch (951 GDD), Seyval (1050 GDD) needs fewer than 1250 GDD, while earlyripening $V$. vinifera needs a little more than 1250 GDD such as Pinot Noir (1251 GDD) or Chardonnay (1267 GDD) (Van Leeuwen et al. 2008). In terms of frost-free days, Pinot Noir and Chardonnay need a minimum of about 160 to 170 days. Hence, the combination of the "very good" thresholds can be seen as an approximation of a combined V. vinifera threshold while "moderate" threshold can be seen as an approximation of hybrid-variety threshold.

Harsh, cold winter temperatures can kill the vines or seriously reduce the production potential of non-hardy grapes such as $V$. vinifera and many French hybrid varieties. Without protection, temperatures below $-17{ }^{\circ} \mathrm{C}$ may kill the primary (as well as the secondary and tertiary) buds. Fortunately, adaptation techniques exist for this problem. This means that the temperature that will effectively kill the primary buds is somewhat lower. In a comprehensive experiment, Willwerth et al. (2014) showed that when vines are under soil, 
the temperature they experience could be as much as $18{ }^{\circ} \mathrm{C}$ different from the ambient temperature. Other techniques, such as covering vines with a polyester material did not perform as well, but still led to a mean difference of 4-to- $6{ }^{\circ} \mathrm{C}$ from ambient temperatures. As such, the threshold used for $V$. vinifera grape varieties will be $-22^{\circ} \mathrm{C}$.

Finally, one aspect that is not covered in this study is late spring frost. Once enough warmth accumulates during spring, the vines are less tolerant to cold temperatures. If frost conditions (i.e., typically lower than $-2{ }^{\circ} \mathrm{C}$ ) arise during this period of the year, it can kill the buds. Using the same PCS approach described in this paper, results show that the probability of late spring frost conditions is constant between 1961-2070 (Supplementary Materials). Although there appears to be a general shift towards earlyspring conditions and longer growing seasons, the length of the transition period between winter conditions (e.g., temperature $<0{ }^{\circ} \mathrm{C}$ ) and spring conditions (e.g., temperature $>0$ ${ }^{\circ} \mathrm{C}$ ) where there is a potential for frost damage does not seem to change greatly, resulting in constant probability of late spring frost.

\subsection{Climate scenarios design}

Interpolation and statistical adjustment of simulated time series The daily climatemodel outputs are interpolated onto the $10 \mathrm{~km}$ National Resources Canada dataset grid (Hutchinson et al. 2009) through a standard Delaunay triangulation. The interpolated value is then corrected using a quantile-quantile mapping statistical adjustment (Themeßl et al. 2011; Grenier et al. 2015) with respect to the high-resolution NRCAN daily dataset. For each Julian day, a transfer function per quantile is estimated between the NRCAN and simulated-time series over the common period (1961-2070) and then applied to the 19612070 simulations. The reference dataset for a particular Julian day is comprised of a 30-day moving window centred on the Julian day of interest.

Probability estimation The probability $P(X>x, t)$ of being over a specified threshold $x$, for the year $t$ is given by:

$$
P(X>x, t)=\frac{1}{N} \sum_{i=1}^{N} w_{i} S i
$$

where $S_{i}$ equals 1 if the value of the (statistically adjusted) simulation is above the specified threshold or 0 otherwise, $\mathrm{N}$ is the total number of simulations and $w_{i}$ is the weight for simulation $S_{i}$. The weighting scheme used is termed "model democracy," where each model has the same weight regardless of the number of runs available. In other words, a model with $n$ runs will have the same weight as a model with $m$ runs.

Resulting probability-time series are then filtered by a Gaussian filter (with parameter $\sigma=5$ ) with the aim of smoothing the inter-annual variability to obtain the long-term component of the probability evolution.

\subsection{Uncertainty on probabilities}

Confidence intervals (CI) associated with the sampling uncertainty are calculated through a standard non-parametric bootstrapping approach (Efron 1979) with the bias corrected and accelerated percentile method (Efron 1987) and 10000 re-sampling iterations. Epistemic uncertainty (e.g., arising from an incomplete understanding of climate processes) is not addressed in this article and is not covered by the bootstrapped CI. 


\section{Results}

\subsection{RCP handling and probability-time series}

Figure 2 shows the sensitivity of three indices of future VP to the Representative Concentration Pathway (RCP) 4.5 and 8.5 forcing scenarios for the Estrie region, located in southeastern Québec and identified as an area where the winegrowing sector could potentially benefit from climate change. As expected, the background-warming trend results in an increased probability of crossing identified climate-thresholds over time. The difference between RCPs becomes apparent around 2030 - 2040, consistent with other studies that examined temperature trends (Hawkins and Sutton 2011; Grenier et al. 2015), and grows larger by 2070, especially for higher-threshold values. Probability-time series shows a monotonic increase for all indices and thresholds.

Figure 3 combines both RCPs into a common estimated probability through a sampling procedure (bootstrapping), where uncertainties due to different RCPs and climate models, as well as natural variability, are taken into account. For a given year, an estimate of the probability of reaching thresholds of each index can be determined (uncertainty being illustrated by the upper and lower bounds). One can then estimate the year when climate-index thresholds are more or less commonly attained, identify when a given region will likely become suitable for wine-grape cultivation, as well as which grape varieties could potentially be produced for this region in the coming decades. The objective is to estimate the occurrence year (OY) of $P(X>x) \geq 0.8$ for each grid points by using the information illustrated in Fig. 3 (single index probability can be found in Supplementary Materials. Note that for brevity, only the weighted mean-probability is given).

\subsection{Composite probability}

Analyzing each index separately is not necessarily optimal: a given year has no real potential if the frost-free season is long but there are not enough growing degree days. Hence, synchronicity between the climate indices is an important prerequisite and the composite probability shown here is simply the probability to exceed specified thresholds across indices. For our purposes, the interest is to pinpoint emerging viticultural regions (new VP) and regions where the suitability for some $V$. vinifera species could increase (improving VP).

Figure 4 presents the probability of having a moderate VP, defined here when CNFD $>156$ days, DDB $10>1000 \mathrm{DD}$ and AWMT $>-30{ }^{\circ} \mathrm{C}$ for time horizons 2050 and 2065. These thresholds represent typical values needed for many hybrid varieties currently grown in southern Québec. As expected, the southern part of the province has a high probability of exceeding these thresholds (and already exceed them quite regularly). Southern parts of the Outaouais region (around $45^{\circ} \mathrm{N}$ and between $75-77^{\circ} \mathrm{W}$ ) and along the St. Lawrence River show promising probabilities for moderate VP in the coming decades and represent new VP.

Figure 5 shows the probability to grow early-ripening $V$. vinifera grape varieties such as Pinot Noir, Merlot, and Chardonnay. Suitability of these varieties is met when $\mathrm{CNFD}>180$ days, DDB $10>1250 \mathrm{DD}$ and AWMT $>-22^{\circ} \mathrm{C}$. While $V$. vinifera varieties have been shown to be vulnerable to temperatures below $-17^{\circ} \mathrm{C}$, a colder threshold is used here as mitigation techniques exist and winter damage to cold temperatures varies by region. For the former, Willwerth et al. (2014) have shown that using geotextiles or soil to cover the vines can lead to effective temperature protection of at least $5{ }^{\circ} \mathrm{C}$. For the latter, Wolf (2008) has shown that the critical low-temperature thresholds vary by region, grape species, 

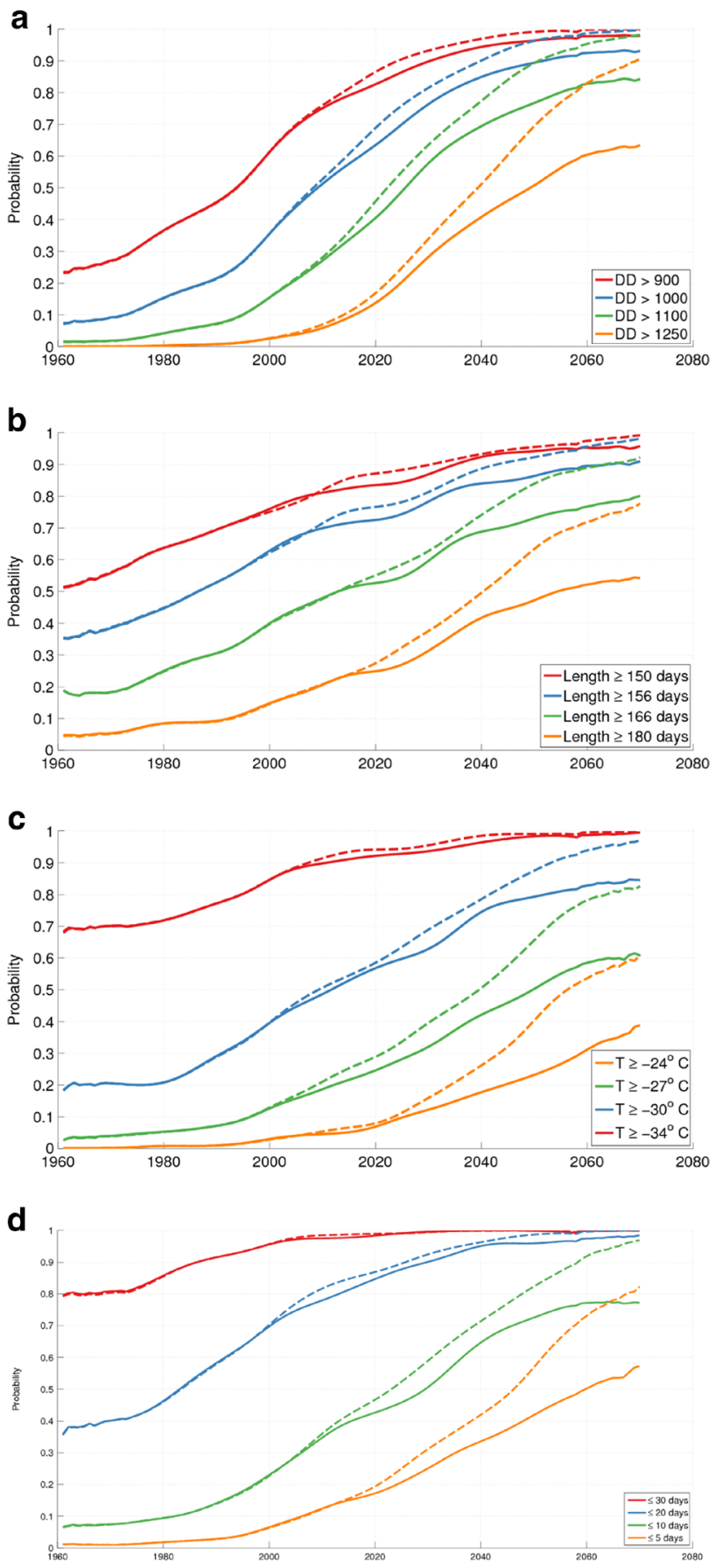

Fig. 2 Time series of probabilities over the Estrie sub-region for a DDB10, b CNFD, c AWMT, and d ANVCD. Probabilities are calculated for each grid points of the sub-region and then spatially averaged. The solid lines represent the simulations using RCP 4.5 and the dashed lines are for simulations using RCP 8.5. A Gaussian filter is applied to smooth out the inter-annual variability 

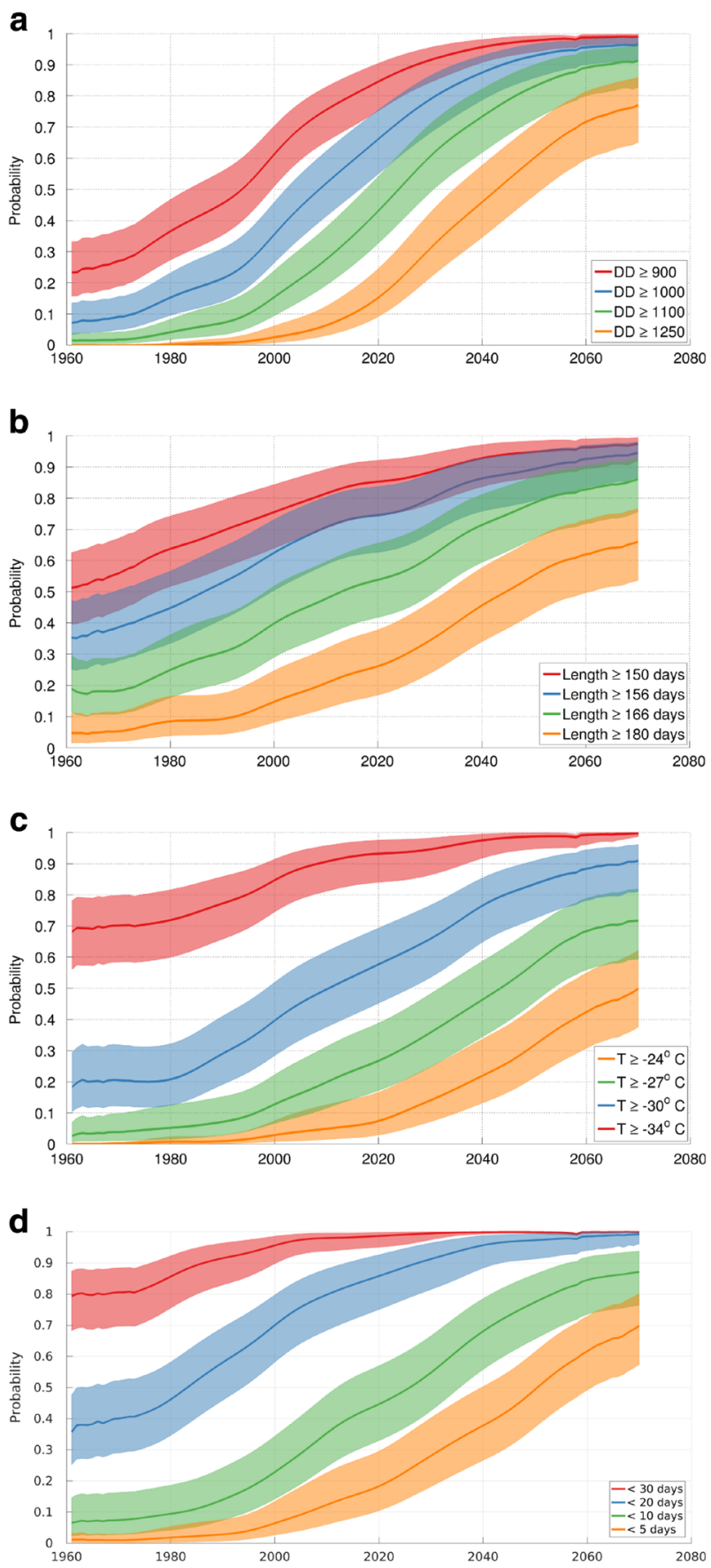

Fig. 3 Time series of probabilities over the Estrie sub-region for a DDB10, b CNFD, c AWMT, and d ANVCD. Probabilities are calculated for each grid points of the sub-region and then spatially averaged. A Gaussian filter is applied to smooth out the inter-annual variability. The solid line is the estimation from the whole ensemble, mixing both RCP (4.5 and 8.5). The confidence interval is calculated though a bootstrapping technique (10 000 iterations) 
a

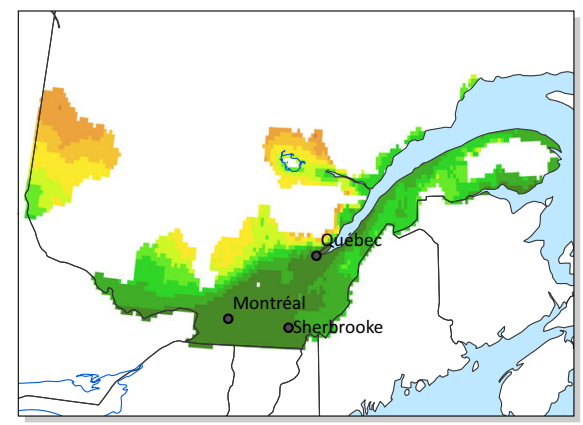

b

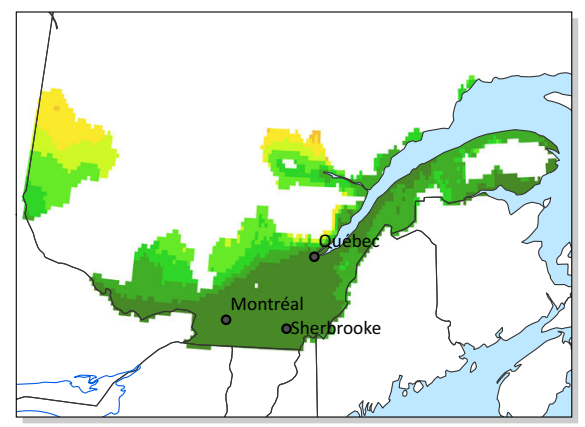

Probability

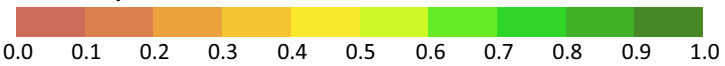

$0 \quad 100 \quad 200 \mathrm{~km}$

Fig. 4 Probability of having more than 1000 DD, 156 consevutive days without frost, a minimal winter temperature higher than $-30{ }^{\circ} \mathrm{C}$ and no more than 20 days with temperature lower than $-22{ }^{\circ} \mathrm{C}$ for the year a 2050 and b 2065. A 10-year interval centered around the year 2050 and 2065 is used to calculate the time-mean probability for year 2050 (2046-2055) and year 2065 (2061-2070)

time of the year and the air temperature immediately preceding the cold outburst. Indeed, the critical temperature for Virginia is about $-22{ }^{\circ} \mathrm{C}$ and this colder limit being a result of "cold acclimation" influenced by high elevations in the Virginia region (Wolf 2008). Interestingly, the VP is high in the southern part of Québec, especially in the Montérégie region, where the probability is higher than $70 \%$ for 2050 and $80 \%$ for 2065 . Montérégie is one of the main viticultural regions of the province and seems poised to remain the prominent region under a warming climate.

a

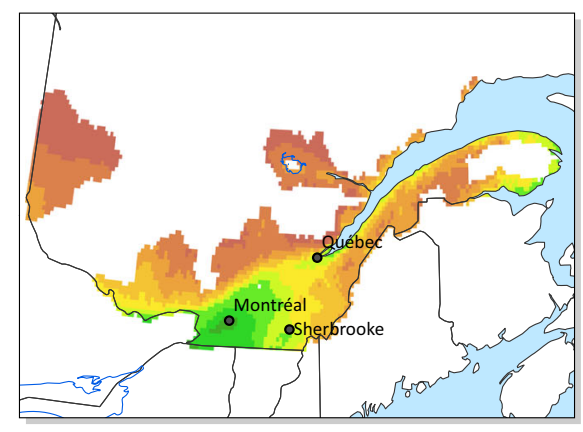

Probability b

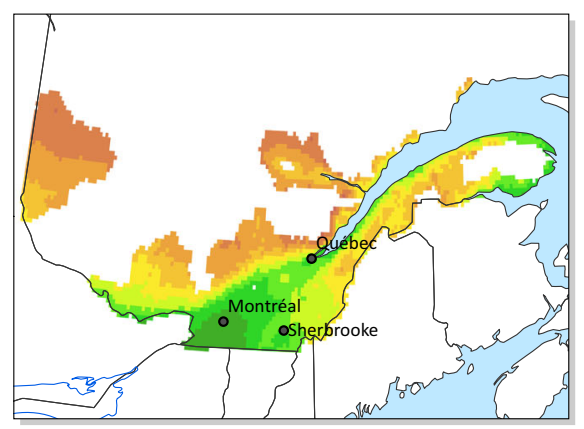

$0 \quad 100 \quad 200 \mathrm{~km}$

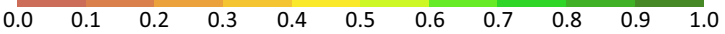

Fig. 5 Probability of having more than 1250 DD, 180 consevutive days without frost, a minimal winter temperature higher than $-22{ }^{\circ} \mathrm{C}$ and no more than 5 days with temperature lower than $-22{ }^{\circ} \mathrm{C}$ for the year a 2050 and b 2065. A 10-year interval centered around the year 2050 and 2065 is used to calculate the time-mean probability for year 2050 (2046-2055) and year 2065 (2061-2070) 
Table 2 Grapevines climate/maturity groupings based on the growing season mean temperature

\begin{tabular}{ll}
\hline Cool & $13-15^{\circ} \mathrm{C}$ \\
Intermediate & $15-17^{\circ} \mathrm{C}$ \\
Warm & $17-19^{\circ} \mathrm{C}$ \\
Hot & $19-22^{\circ} \mathrm{C}$
\end{tabular}

Conclusions of this composite index are clear for 2050 and 2065: VP is relatively high in the southern part of the province (Montérégie, Outaouais, western part of Estrie) and along the St. Lawrence River. What is not clear however, is how these indices should be weighted: is one index more important to overall VP? Considering the protective techniques described above, unequal weights could potentially be considered for a more appropriate assessment. It is understood that growing degree days and the length of the frost-free season hold equal weight (personal communication). However, no clear consensus has been reached among end users about the relative weight of these two indices with respect to winter minimum temperatures. Moreover, the weights could vary spatially.

\subsection{Type of vines}

Using information from Jones (2006) and Hall and Jones (2009), four thermal category have been defined (Table 2). Using the PCS approach, we can estimate the probability of being in a Cool, Intermediate, Warm or Hot thermal region.

Figure 6 shows the category with the highest probability. Most of southern Québec, Outaouais, and St-Lawrence Valley would be located in a Hot thermal regime in 2050 and 2065. From 2050 to 2065, the expansion of the Hot region is significant. Also noted is the disappearance of the Intermediate region between 2050 and 2065. Perhaps surprisingly, the Cool region is not present in 2050 and 2065.

a

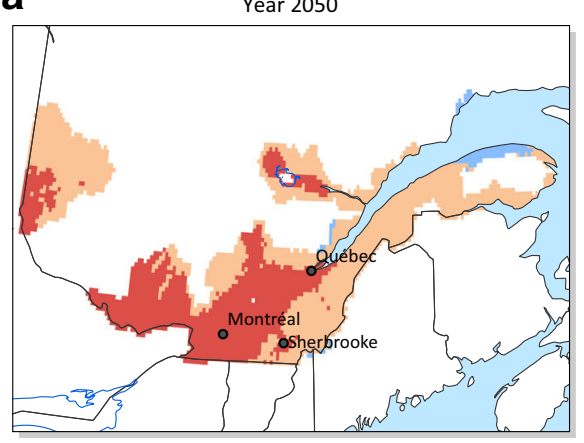

Thermal region

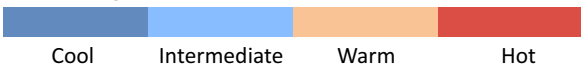

b

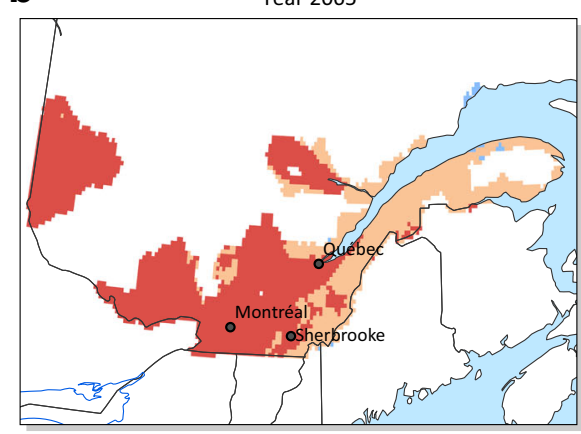

$0 \quad 100 \quad 200 \mathrm{~km}$

Fig. 6 Probability of having a given thermal category for the year a 2050 and b 2065. A 10 -year interval centered around the year 2050 and 2065 is used to calculate the time-mean probability for year 2050 (20462055) and year 2065 (2061-2070) 


\section{Discussion}

\subsection{Interpretation of the probability results}

Actors in the agricultural industry often use historical-occurrence frequencies as a form of probability, working with the formulation "X years out of Y." This formulation might give the wrong picture in a context of non-stationary climate, where historical occurrence does not reflect future climate regime. In this sub-section, we discuss how these concepts (" $\mathrm{X}$ years out of Y" and the PCS approach) can be merged.

Figure 7 shows two ways to see the probability for a given year. Each filled square corresponds to a year (along the $x$ axis) and a given simulation (along the $y$ axis). The filled squares indicate that the given simulation exceeds the prescribed threshold for a given year (the first line [grey squares] represent the NRCAN observation-based product). When the threshold is exceeded, the colour saturation indicates the intensity of the excess (normalized to the maximum of the excess magnitude of the whole ensemble and time period). Each line (i.e., scenario) is a possible climate trajectory. The natural variability of the climate ensures that the actual trajectory will be different than the PCS estimation or any climate trajectory. However, given a number of realizations large enough for the observed climate (which is impossible to do outside of a thought experiment), the observed probability would plausibly converge towards $P(X>x, t)$.

The first approach is the one where the user looks at a single simulation over a given period of years and answers such questions as "How many exceedances do I have over 10 years?" The second approach, represented by the black line, is the method proposed in

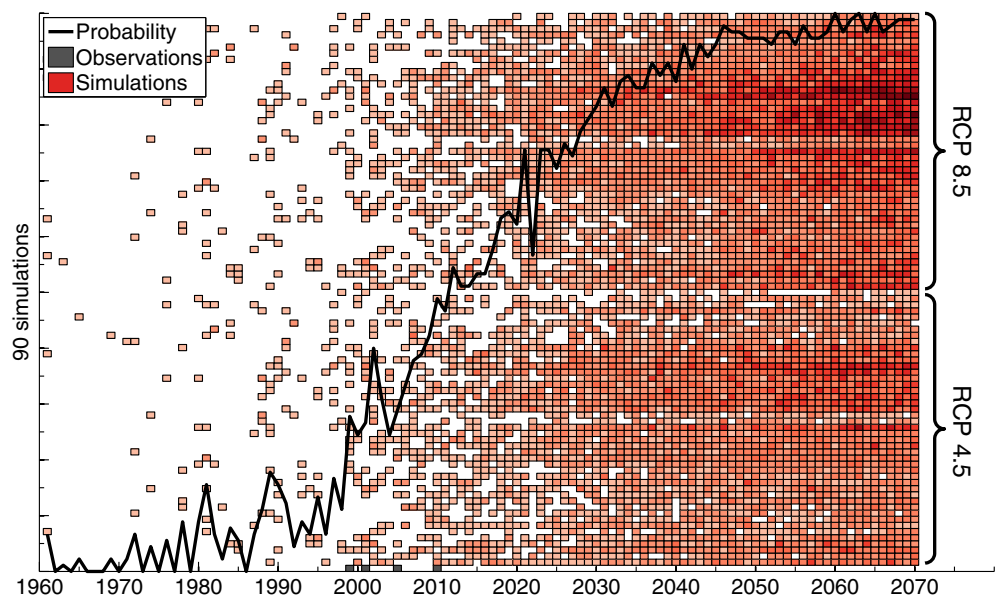

Fig. 7 Occurrence and intensity of excess for observations (grey) and every simulations (red) used for DDB10 for threshold value 1100 DD for a given grid points located in the Estrie subregion. An empty square means that the prescribed threshold is not exceeded. A colored square indicates that the threshold has been exceeded. Color saturation relates to the intensity of the excess (normalized with the maximum excess found in the whole ensemble and time period). The black line is the unweighted proportion (i.e., "one simulation gets one vote," instead of "one model gets one vote" used in the study) of simulations that are over the threshold 
this article: the proportion of scenarios exceeding a prescribed threshold for a given year, effectively reducing the information of the ensemble scenario for that year.

To see how we can reconcile the concept of "X years out of $\mathrm{Y}$ " and the PCS approach, we take the year 2010 (other years - 2030, 2050 and 2060 - have been tested and show the same behaviour - not shown). The black line from Fig. 7 shows that the probability estimation for 2010 (the PCS approach) is approximately 50\% (which means that about half of the scenarios for 2010 give values over 1100 DD). We compare this estimation with each simulation between 2006 - 2015 to see the possible trajectory that the climate could have taken (i.e., each simulation being a possible trajectory that southern Québec could see), as shown in Fig. 8 which indicates the number of years (between 2006-2015) where DDB10 is over 1100 DD. The spread of the distribution highlights the fact that even though the best estimate is close to 50\% (PCS estimation and the scenario's distribution mean), the possible trajectories for the individual scenarios are numerous and range from 1 to 10 . Interestingly, the mean value of the possible trajectory is similar to the ensemble estimation. This is caused by a compensation of the influence of climate change on the data. In other words, by using 2006 - 2015 to estimate the mean trajectory for 2010, we have years after 2010 that are (usually) warmer than 2010 and years before 2010 are usually colder than 2010. It is important to emphasize that in reality, we will see a single realization and the " $X$ years out of Y" for any given decade will be different than the PCS estimation, mainly due to natural climate variability.

These results suggest that the PCS approach gives results close to the usual user formulation ("X years out of Y") and that users could use the estimated PCS probabilities and associate them with their standard formulation, without much loss of generality. This also means that the PCS approach gives a good estimate of the climatological probabilities of exceeding a given threshold, in phase with the background climate change forcing, which is not the case with historical observations. However, this result indicates that natural variability creates a rather large distribution of possible trajectories for any given decade. We

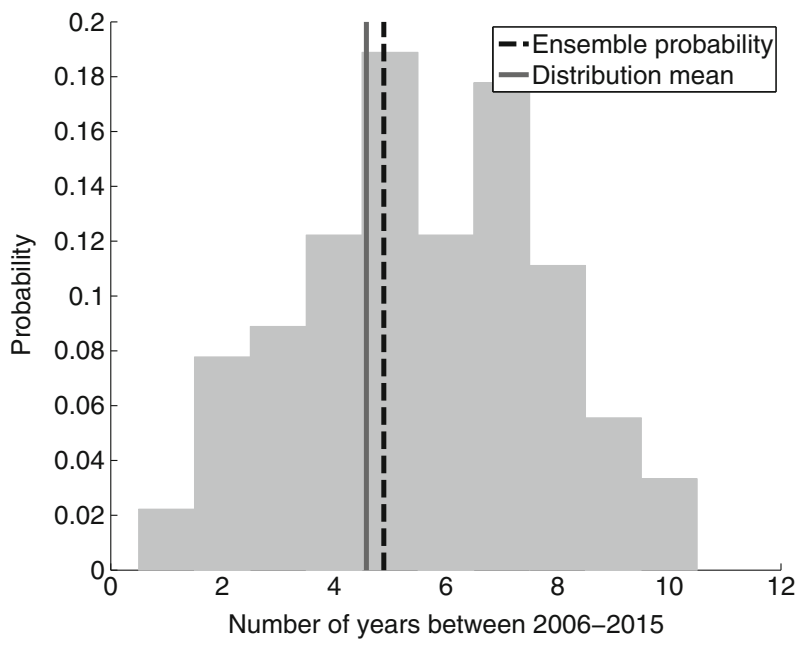

Fig. 8 Distribution of the number of years for the whole ensemble that DDB10 is over 1100 DD for 1 grid point between the years 2006-2015. The black dashed line is the estimated probability with the PCS approach. The grey plain line is the distribution mean 
note that this possible difference between the estimated PCS probability and the actual climate trajectory probability for a given decade also applies to most, if not all, climatological statistics.

\subsection{Uncertainties and limitations}

Along with the RCP-related assumptions discussed in Section 2, one important limitation of the PCS approach is that the ensemble used might have common biases (e.g., processes unknown to climatologists). Hence, the ensemble is not guaranteed to represent the real climate system, meaning that estimated probabilities can have an associated bias. Moreover, our results represent only probabilities from a given "opportunity ensemble" (Tebaldi and Knutti 2007). The inclusion of other models and/or members will have an effect on the estimated probabilities. The potential extent of this effect is partially evaluated (see Supplementary Material). It must be noted that these biases represent a fundamental limitation in climate assessment from the use of climate models, and are not specific to the PCS approach presented here.

Refining the climate indices is also something that could be examined. Current research indicates that periods of very high temperatures are unfavourable for crops in general (White et al. 2006; Schlenker and Roberts 2009) and may affect vines as well. Our indices of degree-days are calculated by naively adding temperature units over a given threshold and do not account for potential damage caused by very high temperatures. Since we can expect higher extreme temperatures in the coming century (IPCC 2012), this effect, as well as other extremes such as wind gusts and heavy rains, should potentially be considered in future assessments.

This study did not look at future precipitation regimes for Québec. At the end of the viticulture season, grapes benefit from dry conditions (helping sugar concentration). Historical precipitation conditions are not a limiting/helping factor in Québec. However, future climate scenarios show an increase of precipitation over the eastern part of North America. This should be documented, whether or not this increase limits viticulture.

An important protection measure against harsh cold is snow cover. Projections from climate models show a possible reduction in snow cover in southern Québec, combined with annual winter temperatures below the critical threshold for $V$. vinifera of $-17{ }^{\circ} \mathrm{C}$. This means that growers will face another challenge and incur additional costs associated with alternative winter thermal protection.

Finally, even though sunshine hours are currently higher than in other traditional viticultural regions such as Bordeaux and New Zealand (Jones 2012), it is unclear how cloud cover will affect future sunshine hours in southern Québec. Cloud physics in climate models being mostly associated with sub-grid parameterizations, a rigorous assessment of future cloud cover is beyond the scope of this article and remains a challenging topic in climate research (Bony et al. 2015).

\section{Summary}

Probabilistic climate scenarios (PCS) of viticultural potential (VP) are provided for the province of Québec, in northeastern North America. Results indicate that climate change presents an opportunity for the northern vine-growing sector and that the PCS approach can provide rich information to a decision-making framework. However, potential negative effects related to climate change should not be cast aside: diseases, increased or new types 
of insect infestation, as well as a modified frost-thaw cycle represent only a few new challenges. Maps of occurrence year represent an interesting tool for potential growers who wish to evaluate the suitability of different regions for a given grape variety.

Québec can expect new wine-producing regions to emerge in coming decades (the Outaouais and along the St Lawrence River), where the probability of minimal growing degree days and season length is high. The southern part of the province has been a vinegrowing region for the past three decades and should continue to be in the coming decades, with the added benefit of widespread potential for early-ripening varieties such as Vitis vinifera. However, winter temperatures continue to be a limiting factor, even for the hybrid varieties currently grown in Québec. Fortunately, mitigation methods, such as using soil or geotextile fabric for thermal protection, can be easily applied. These techniques should remain necessary in the coming decades, despite projected warmer conditions.

Although the focus of the study is in Québec, other Canadian provinces such as Ontario and British Columbia should see similar results. Similarly, although the focus of the study is on Québec, studies of other Canadian provinces such as Ontario and British Columbia should yield similar results. Similarly, other portions of the world with cold conditions are likely to experience similar phenomena. Provided that sufficient observations are available for the statistical adjustment of the simulated time series and that relevant climate indices can be defined for a region, this study can be replicated for any part of the world. The approach gives a rich overview of the impacts and economic potential of climate change for the wine industry and policymakers.

Acknowledgments We acknowledge the World Climate Research Programme's Working Group on Coupled Modeling, which is responsible for CMIP, and we thank the climate modeling groups for producing and making available their model output. For CMIP the U.S. Department of Energy's Program for Climate Model Diagnosis and Intercomparison provides coordinating support and led development of software infrastructure in partnership with the Global Organization for Earth System Science Portals. We also thank Dan McKenney and the team at the Canadian Forest Service of Natural Resources Canada for providing the observational product used.

Author Contributions P.R., P.G., E.B., and D.C. conceived the methodology. E.B. developed the climate indices. P.R. and P.G. wrote code and P.R., P.G., E.B., T.L., A.B., G.B. and D.C. analysed output data. T.L. conceived the maps. P.R. wrote the manuscript and P.G., E.B., T.L., A.B., G.B. and D.C. reviewed the manuscript.

Open Access This article is distributed under the terms of the Creative Commons Attribution 4.0 International License (http://creativecommons.org/licenses/by/4.0/), which permits unrestricted use, distribution, and reproduction in any medium, provided you give appropriate credit to the original author(s) and the source, provide a link to the Creative Commons license, and indicate if changes were made.

\section{Appendix: List of acronyms}

ANVCD Annual number of very cold days

AWMT Annual winter minimum temperature

CMIP5 Coupled Model Intercomparison Project Phase 5

CNFD Consecutive no frost days

DDB10 Degree-days base $10{ }^{\circ} \mathrm{C}$

ESM Earth System Model

PCS Probabilistic Climate Scenarios

RCP Representative Concentration Pathways

VP Viticultural Potential 


\section{References}

Barriault E, Fonclara R, Bourgeois G, Drouin A, Grenon L, Michaud A, Plouffe D, Venneman D (2013) Grille évaluation du potentiel viticole. Technical report

Battaglini A, Barbeau G, Bindi M, Badeck F-W (2009) European winegrowers' perceptions of climate change impact and options for adaptation. Reg Environ Chang 9(2):61-73

Bony S, Stevens B, Frierson DMW, Jakob C, Kageyama M, Pincus R, Shepherd TG, Sherwood SC, Siebesma AP, Sobel AH, Watanabe M, Webb MJ (2015) Clouds, circulation and climate sensitivity. Nat Geosci 8(4):261-268

Dubois J-MM (2001) De la Nouvelle-France à nos jours : une tradition viticole tenace au Québec. Cap-auxDiamants 65:32-37

Efron B (1979) Bootstrap methods: another look at the jackknife. Ann. Stat. 7(1):1-26

Efron B (1987) Better bootstrap confidence intervals. J Amer Stat Assoc 82(397):171-185

Gennaretti F, Sangelantoni L, Grenier P (2015) Toward daily climate scenarios for Canadian Arctic coastal zones with more realistic temperature-precipitation interdependence. J Geophys Res Atmosp 120(23):11,811-862,877

Grenier P, de Elía R, Chaumont D (2015) Chances of short-term cooling estimated from a selection of CMIP5-based climate scenarios during 2006-2035 over Canada. J Clim.

Hall A, Jones G (2009) Effect of potential atmospheric warming on temperature-based indices describing Australian winegrape growing conditions. Aust J Grape Wine Res 15(2):97-119

Hall J, Twyman C, Kay A (2005) Influence diagrams for representing uncertainty in climate-related propositions. Clim Change 69(2-3):343-365

Hannah L, Roehrdanz PR, Ikegami M, Shepard AV, Shaw MR, Tabor G, Zhi L, Marquet PA, Hijmans RJ (2013) Climate change, wine, and conservation. Proc Nat Acad Sci 110(17):6907-6912

Hawkins E, Sutton R (2011) The potential to narrow uncertainty in projections of regional precipitation change. Clim Dyn 37(1):407-418

Hutchinson MF, McKenney DW, Lawrence K, Pedlar JH, Hopkinson RF, Milewska E, Papadopol P (2009) Development and testing of Canada-wide interpolated spatial models of daily minimum-maximum temperature and precipitation for 1961-2003. J Appl Meteorol Climatol 48(4):725-741

IPCC (2012) Managing the risks of extreme events and disasters to advance climate change adaptation. A special report of working groups $\mathrm{i}$ and II of the intergovernmental panel on climate change. Cambridge University Press, Cambridge

Jones GV (2006) Climate and terroir: impacts of climate variability and change on wine. Technical report, Geological Association of Canada, St. John's. Newfoundland

Jones NK (2012) The influence of recent climate change on wine regions in Quebec, Canada. J Wine Res 23(2):103-113

Jones GV, Webb LB (2010) Climate change, viticulture, and wine: challenges and opportunities. J Wine Res 21(2-3):103-106

Jones G, White M, Cooper O, Storchmann K (2005) Climate change and global wine quality. Clim Change 73(3):319-343

Palmer TN, Räisänen J (2002) Quantifying the risk of extreme seasonal precipitation events in a changing climate. Nature 415(6871):512-514

Parker WS (2010) Whose probabilities? Predicting climate change with ensembles of models. Philos Sci $77(5)$

Schlenker W, Roberts MJ (2009) Nonlinear temperature effects indicate severe damages to U.S. crop yields under climate change. Proc Nat Acad Sci 106(37):15594-15598

Shaw AB (1999) The emerging cool climate wine regions of eastern Canada. J Wine Res 10(2):79-94

Taylor KE, Stouffer RJ, Meehl GA (2011) An overview of CMIP5 and the experiment design. Bull Amer Meteorol Soc 93(4):485-498

Tebaldi C, Knutti R (2007) The use of the multi-model ensemble in probabilistic climate projections. Philos Trans. Series A Math Phys Eng Sci 365(1857):2053-75

Themeß1 MJ, Gobiet A, Leuprecht A (2011) Empirical-statistical downscaling and error correction of daily precipitation from regional climate models. Int J Climatol 31(10):1530-1544

Themeß1 MJ, Gobiet A, Heinrich G (2012) Empirical-statistical downscaling and error correction of regional climate models and its impact on the climate change signal. Clim Change 112(2):449-468

Van Leeuwen C, Garnier C, Agut C, Baculat B, Barbeau G, Besnard E, Bois B, Boursiquot J-M, Chuine I, Dessup T (2008) Heat requirements for grapevine varieties is essential information to adapt plant material in a changing climate. In: 7. Congrès International des Terroirs Viticoles. 2008-05-192008-0523, Nyon, CHE 
White MA, Diffenbaugh NS, Jones GV, Pal JS, Giorgi F (2006) Extreme heat reduces and shifts United States premium wine production in the 21st century. Proc Nat Acad Sci 103(30):11217-11222

Willwerth J, Ker K, Inglis D (2014) Best management practices for reducing winter injury in grapevines. Technical report, Cool Climate Oenology \& Viticulture Institute, Brock University, Saint Catharines

Wolf TK (2008) Wine grape production guide for eastern North America. Natural Resource, Agriculture, and Engineering Service (NRAES) Cooperative Extension 